\title{
Conversion to purpurogallin, a key step in the mechanism of the potent xanthine oxidase inhibitory activity of pyrogallol
}

Sari Honda, Yuya Fukuyama, Hisashi Nishiwaki, Akiko Masuda, Toshiya Masuda

\begin{tabular}{|c|l|}
\hline Citation & Free Radical Biology and Medicine, 106; 228-235 \\
\hline Issue Date & 2017-05 \\
\hline Type & Journal Article \\
\hline Textversion & author \\
\hline $\begin{array}{c}\text { Supplementary } \\
\text { material }\end{array}$ & $\begin{array}{l}\text { Supplementary material is available at } \\
\text { https://doi.org/10.1016/j.freeradbiomed.2017.02.037. }\end{array}$ \\
\hline Rights & $\begin{array}{l}\text { C } 2015 \text { Elsevier Ltd. This manuscript version is made available under the } \\
\text { CC-BY-NC-ND 4.0 License. http://creativecommons.org/licenses/by-nc-nd/4.0/. }\end{array}$ \\
& $\begin{array}{l}\text { This is the accept manuscript version. The article has been published in final form } \\
\text { at https://doi.org/10.1016/j.freeradbiomed.2017.02.037. }\end{array}$ \\
\hline DOI & \begin{tabular}{l}
$10.1016 / j . f r e e r a d b i o m e d .2017 .02 .037$ \\
\hline
\end{tabular} \\
\hline
\end{tabular}

\author{
Self-Archiving by Author(s) \\ Placed on: Osaka City University
}

HONDA, S., FUKUYAMA, Y., NISHIWAKI, H., MASUDA, A., \& MASUDA, T. (2017). Conversion to purpurogallin, a key step in the mechanism of the potent xanthine oxidase inhibitory activity of pyrogallol. Free Radical Biology and Medicine. 106, 228-235. 
Conversion to purpurogallin, a key step in the mechanism of the potent xanthine oxidase inhibitory activity of pyrogallol

Sari Honda ${ }^{a}$, Yuya Fukuyama ${ }^{a}$, Hisashi Nishiwaki ${ }^{\mathrm{b}}$, Akiko Masuda ${ }^{\mathrm{c}}$, and Toshiya Masuda,

${ }^{a}$ Graduate School of Human Life Science, Osaka City University, Osaka 558-8585,

Japan

${ }^{b}$ Graduate School of Agriculture, Ehime University, Matsuyama, 790-8566, Japan

${ }^{c}$ Faculty of Human Life Science, Shikoku University, Tokushima 771-1192, Japan

*Corresponding Author: Fax: +81 6665 2813; e-mail: masuda_t@life.osaka-cu.ac.jp (T. Masuda) 
Keywords: Pyrogallol, Purpurogallin, Xanthine oxidase inhibition, Chemical

mechanism, Physiological $\mathrm{pH}$

\section{ABSTRACT}

In this study, the mechanism of the xanthine oxidase (XO) inhibitory activity of pyrogallol, the main inhibitor found in roasted coffee, was investigated. Pyrogallol was unstable and readily converted to purpurogallin in a $\mathrm{pH} 7.4$ solution, a physiological model of human body fluids. The XO inhibitory activity of the produced purpurogallin was higher than that of pyrogallol, as evidenced by comparing their $\mathrm{IC}_{50}$ values $(0.2$ $\mu \mathrm{mol} \mathrm{L} \mathrm{L}^{-1}$ for purpurogallin, $1.6 \mu \mathrm{mol} \mathrm{L}^{-1}$ for pyrogallol). The $\mathrm{XO}$ activity of pyrogallol was enhanced by pre-incubation in $\mathrm{pH} 7.4$ solution. Although the initial XO inhibitory activity of 4-methylpyrogallol was weak $\left(\mathrm{IC}_{50} 33.3 \mu \mathrm{mol} \mathrm{L}^{-1}\right)$, its XO inhibitory activity was also enhanced by pre-incubation in the $\mathrm{pH} 7.4$ solution. In contrast, 5-methylpyrogallol, which could not be transformed into corresponding purpurogallin derivatives, did not show XO inhibitory activity before or after incubation in $\mathrm{pH} 7.4$ solution. Molecular docking simulations clarified that purpurogallins have stronger affinities for XO than corresponding pyrogallols. These results revealed that the potent 
XO inhibitory activity seemingly observed in pyrogallol is actually derived from its chemical conversion, under alkaline conditions, into purpurogallin. 


\section{Introduction}

Xanthine oxidase (XO), the final enzyme in purine catabolism of humans, catalyses the oxidation reactions of hypoxanthine and xanthine. The reactions produce uric acid and reactive oxygen species such as superoxide and hydrogen peroxide. It is well known that the onset of gout is due to an over-accumulation of plasma uric acid: this over-accumulation is believed to be related to eating habits [1]. Therefore, in spite of being a classical disease, gout is now also recognized as a current lifestyle-related disease, with recent increases in the number of patients experiencing it [2].

Cardiovascular disease is another lifestyle-related disease, and it is well known to be related to oxidative stress caused by superoxide, hydrogen peroxide, nitric oxide, and their metabolites (hydroxyl radical, peroxynitrite, etc.) [3]. Thus, inhibition of the over-working of XO is important in preventing such lifestyle-related diseases [4]. For gout treatment, several synthetic XO inhibitors were developed in the 1950s and1960s; however, they are toxic to human organs [5]. Therefore, several recent investigations have sought safer and more effective XO inhibitors from natural sources, including foods and traditional herbs [6]. Coffee is the most popular beverage in the world; it is comes from the beans of tropical Caffea arabica trees (and related species), and is made 
by roasting, grinding, and brewing the beans. In epidemiological studies published in 2007, Choi et al. [7] reported that a coffee drinking habit significantly reduces the incidence of gout. They also showed that coffee reduced uric acid levels in the serum of in coffee drinkers $[8,9]$. These results indicated that coffee could be a promising source of the XO inhibitors, and prompted us to seek those inhibitory compounds in coffee as candidates for medicines to treat gout. In a previous study, we observed that XO-inhibitory activity only in roasted coffee beans, and not in green or dried beans [10]. We have also isolated XO inhibitors from hot-water extracts of roasted coffee beans, and identified them as pyrogallol and several chlorogenic lactones [11]. Based on quantitative analyses and evaluations of the respective activity efficiencies of $\mathrm{XO}$ inhibitors, we hypothesized that pyrogallol was the main contributor of the XO-inhibitory activities in roasted coffee.

Pyrogallol (1,2,3-trihydroxybenzene) is a simple polyphenol that bears the decarboxylated structure of gallic acid, which itself is distributed widely in plants as a component of hydrolysable tannin. Polyphenols have high reactivity for radical trapping and reducing reactions [12], and this reactivity is enhanced under alkaline conditions [13]. Therefore, the high reactivity and resulting structural changes of pyrogallol must be studied chemically to clarify its XO-inhibitory mechanism. In this paper, we report 
on the relation between pyrogallol's $\mathrm{XO}$ inhibition and reactivity at $\mathrm{pH} 7.4$ as a model of physiological conditions, and we discuss the results of our simulations of the molecular docking of pyrogallol (and its related substances) with XO.

\section{Materials and methods}

\subsection{Materials}

Pyrogallol, 5-methylpyrogallol, and 2,3,4-trihydroxybenzaldehyde were purchased from Tokyo Kasei (Tokyo, Japan). Sodium cyanoborohydride was purchased from Sigma-Aldrich Japan (Tokyo, Japan). Xanthine oxidase from buttermilk (ca. 0.3 units $\mathrm{mg}^{-1}$ ) was obtained from Oriental Yeast (Tokyo, Japan). All other reagents and solvents were purchased as extra pure grade or HPLC grade from Nacalai Tesque (Kyoto, Japan).

\subsection{General procedure}

NMR spectra were obtained from a JNM-ECZ400S (JEOL, Tokyo, Japan) 
using the manufacture provided pulse sequences. MS spectra were measured using a JMS-T100 spectrometer (JEOL) with direct analysis at real time (DART) ionization and time of flight (TOF) measuring mode under the following conditions: orifice $1,10 \mathrm{~V}$; orifice 2, $5 \mathrm{~V}$; ring lens, $10 \mathrm{~V}$; helium gas pressure, $0.5 \mathrm{MPa}$, flow rate of $10 \mathrm{~L} \mathrm{~min}^{-1}$; ion resource temperature, $350^{\circ} \mathrm{C}$; grid voltage positive, $400 \mathrm{~V}$ for positive mode. Elemental compositions of analyzed compounds were calculated using MassLynx software (v. 4.1, Waters, MA, USA). Analytical HPLC was performed using a PU-4180 quaternary gradient pump (JASCO, Tokyo, Japan) equipped with an MD-4015 photodiode array detector (JASCO), a CTO-10ASVP column oven (Shimadzu, Kyoto, Japan), and an AS-4150 intelligent sampler (JASCO). Data were analyzed using the ChromNAV software (v.2, JASCO). Preparative HPLC was performed using an LC-6AD pump (Shimadzu) equipped with an SPD-6A UV detector (Shimadzu).

\subsection{Assay for xanthine oxidase inhibition}

The XO inhibitory assay was carried out according to a previously reported method, with modification [14]. The reaction medium consisted of $10 \mu \mathrm{L}$ of $1 \mathrm{mmol} \mathrm{L}^{-1}$ xanthine in DMSO, and $160 \mu \mathrm{L}$ of $12.5 \mathrm{mmol} \mathrm{L}^{-1}$ phosphate buffer (pH 7.4). This 
solution was pre-heated at $37^{\circ} \mathrm{C}$ for $5 \mathrm{~min}$. To this solution was added $10 \mu \mathrm{L}$ of the test

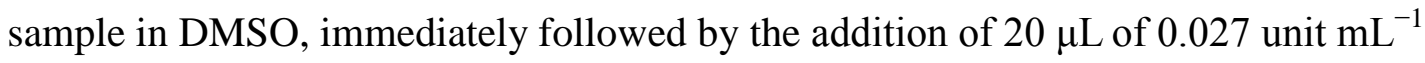
XO solution (pH 7.4 phosphate buffer). After incubation at $37^{\circ} \mathrm{C}$ for $10 \mathrm{~min}, 25 \mu \mathrm{L}$ of $3 \% \mathrm{HClO}_{4}$ in aqueous solution was added to quench the reaction. An aliquot $(20 \mu \mathrm{L})$ of the solution was injected into an HPLC column to quantify the uric acid produced. The HPLC analysis was performed under the following conditions. Column, $250 \mathrm{~mm} \times 4.6$ mm, i.d., $5 \mu \mathrm{m}$, Mightysil RP-18 GP Aqua (Kanto Chemical, Tokyo, Japan); flow rate, $1.0 \mathrm{~mL} \mathrm{~min}^{-1}$; solvent, [methanol-0.1\% phosphoric acid in water $(2.5: 97.5, \mathrm{v} / \mathrm{v})$ ]; detection wavelength, $290 \mathrm{~nm}$; temperature, $35^{\circ} \mathrm{C}$. Percent inhibition was calculated according to the following equation: inhibition $(\%)=[($ peak area of uric acid in control experiment $)-($ peak area of uric acid in sample experiment $)] \times 100 /($ peak area of uric acid in control experiment).

2.4. Stability test and measurements of pyrogallol's XO-inhibitory activity at various $p H$ conditions

At $37^{\circ} \mathrm{C}, 10 \mu \mathrm{L}$ of pyrogallol in $\mathrm{H}_{2} \mathrm{O}\left(4 \mathrm{mmol} \mathrm{L}^{-1}\right)$ was added to $190 \mu \mathrm{L}$ of phosphate buffer solution $\left(12.5 \mathrm{mmol} \mathrm{L}^{-1}\right)$ under various $\mathrm{pH}$ conditions. An aliquot (20 
$\mu \mathrm{L}$ ) was taken from the solution immediately after addition of pyrogallol and again after 10 min had elapsed. The solution was analysed via HPLC under the following conditions. Column, Cosmosil 5C18-AR-II (4.6 x $250 \mathrm{~mm})$; solvent, [0.1\% phosphoric acid in water- $\left.\mathrm{CH}_{3} \mathrm{CN}(95: 5, \mathrm{v} / \mathrm{v})\right]$; flow rate, $1.0 \mathrm{~mL} \mathrm{~min}^{-1}$; detection wavelength: 268 nm. These procedures were repeated using each of several phosphate buffer solutions of different $\mathrm{pHs}$ and the $\mathrm{XO}$ inhibitory activity of each solution was measured by the same procedure described above.

\subsection{Preparation and identification of chemicals}

2.5.1. 4-Methylpyrogallol. To an acetic acid solution (10 mL) of

2,3,4-trihydroxybenzaldehyde $(0.5 \mathrm{~g})$ was added sodium cyanoborohydride $(0.5 \mathrm{~g})$ at $23{ }^{\circ} \mathrm{C}$, and then the solution was heated at $60{ }^{\circ} \mathrm{C}$ with stirring for $2 \mathrm{~h}$. After the solvent was removed under reduced pressure at $40{ }^{\circ} \mathrm{C}$, the obtained residue was purified by silica gel column chromatography (NAM-300H, Nagara Science, Gifu, Japan) eluted with $\mathrm{CH}_{2} \mathrm{CH}_{2}-\mathrm{CH}_{3} \mathrm{OH}=20: 1 \sim 10: 1$ to give 4-methylpyrogalol (0.21 g). ${ }^{1} \mathrm{H}$ NMR (400 MHz in acetone- $\left.\mathrm{d}_{6}\right) \delta$ ppm $2.14\left(3 \mathrm{H}, \mathrm{s}, 4-\mathrm{CH}_{3}\right), 6.32(1 \mathrm{H}, \mathrm{d}, J=8.0 \mathrm{~Hz}, \mathrm{H} 5), 6.45(1 \mathrm{H}, \mathrm{d}$, $J=8.0 \mathrm{~Hz}, \mathrm{H} 6), 7.13(1 \mathrm{H}$, brs, OH), $7.26(1 \mathrm{H}$, brs, OH), 7.85 (1H, brs, OH); DART-MS 
$\mathrm{m} / \mathrm{z} 141[\mathrm{M}+\mathrm{H}]^{+}$.

2.5.2. Purpurogallin. Preparation was carried out according to a reported

method [15]. To a suspension of pyrogallol (2 $\mathrm{g}$ ) in small amount of $\mathrm{H}_{2} \mathrm{O}$ was dropwise added $\mathrm{NaIO}_{3}(1.6 \mathrm{~g})$ in $\mathrm{H}_{2} \mathrm{O}(20 \mathrm{~mL})$ at $0{ }^{\circ} \mathrm{C}$. After addition, the dark red precipitate formed was filtered. The red powder was recrystallized with acetic acid to give purpurogallin (1.0 g). UV-VIS (in $\mathrm{CH}_{3} \mathrm{CN}-\mathrm{H}_{2} \mathrm{O}$ ), $\lambda \max (\mathrm{nm}) 280,300,368$, and 428; DART-MS m/z $221[\mathrm{M}+\mathrm{H}]^{+} ;{ }^{1} \mathrm{H}$ NMR $\left(400 \mathrm{MHz}\right.$ in DMSO- $\left.d_{6}\right) \delta p p m 6.72(1 \mathrm{H}, \mathrm{dd}$, $J=15.2$ and $12.4 \mathrm{~Hz}, \mathrm{H} 8), 6.86(1 \mathrm{H}, \mathrm{s}, \mathrm{H} 1), 7.07(1 \mathrm{H}, \mathrm{d}, J=12.4$ and $1.2 \mathrm{~Hz}, \mathrm{H} 7), 7.29$ (1H, brd, H9).

2.5.3. 1,7-Dimethylpurpurogalin. 4-Methylpyrogallol (100 mg) was dissolved in a phosphate buffer ( $\mathrm{pH} 7.4,71 \mathrm{~mL})$ and then stirred at $40{ }^{\circ} \mathrm{C}$ for 1 day. Red precipitated formed was filtered to give $27 \mathrm{mg}$ of 1,7-dimethylpurpurogallin. UV-VIS (in $\mathrm{CH}_{3} \mathrm{CN}-\mathrm{H}_{2} \mathrm{O}$ ), $\lambda \max (\mathrm{nm}) 284,308,384$, and 440; DART-MS m/z $249[\mathrm{M}+\mathrm{H}]^{+} ;{ }^{1} \mathrm{H}$ NMR (400 MHz in $\left.\mathrm{CD}_{3} \mathrm{OD}\right)$ dppm $2.37\left(3 \mathrm{H}, \mathrm{s}, 7-\mathrm{CH}_{3}\right), 2.42\left(3 \mathrm{H}, \mathrm{s}, 1-\mathrm{CH}_{3}\right), 6.78(1 \mathrm{H}$, d, $J=12.4 \mathrm{~Hz}, \mathrm{H} 8), 7.53(1 \mathrm{H}, \mathrm{d}, J=12.4 \mathrm{~Hz}, \mathrm{H} 9)$. NOEs were observed $1.7 \%$ between the peaks at 2.37 and $6.78 \mathrm{ppm}, 0.5 \%$ between the peaks at 2.37 and $7.53 \mathrm{ppm}$, and $4.2 \%$ between the peaks at 2.42 and $7.53 \mathrm{ppm}$. 
2.6. Time-course analysis of the conversion of pyrogalolls to purpurogallins and

XO-inhibitory activity of the reaction solutions

To $950 \mu \mathrm{L}$ of phosphate buffer (12.5 $\left.\mathrm{mmol} \mathrm{L}^{-1}, \mathrm{pH} 7.4\right), 50 \mu \mathrm{L}$ of DMSO

pyrogalloll or related compounds-solution (consisting of $400 \mu \mathrm{mol} \mathrm{L} \mathrm{L}^{-1}$ pyrogaloll, 4,000

$\mu \mathrm{mol} \mathrm{L} \mathrm{L}^{-1}$ 4-methylpyrogallol, or 4,000 $\mu \mathrm{mol} \mathrm{L}^{-1}$ 5-methylpyrogallol) was added, and the solution was incubated at $37^{\circ} \mathrm{C}$ for $4 \mathrm{~h}$. At different time intervals $(0,0.5,1,2$, and $4 \mathrm{~h})$, a $160 \mu \mathrm{L}$ aliquot was taken from the solution and then acidified by adding $3 \% \mathrm{HClO}_{4}$ aq. $(16 \mu \mathrm{L})$. Twenty $\mu \mathrm{L}$ of the solution was analyzed by HPLC under following conditions. Column, $250 \mathrm{~mm} \times 4.6 \mathrm{~mm}$, i.d., $5 \mu \mathrm{m}$, Cosmosil 5C18-AR-II (Nacalai); flow rate, 1.0 $\mathrm{mL} \min ^{-1}$; solvent $\mathrm{A},[0.1 \%$ phosphoric acid in water]; solvent $\mathrm{B}$, acetonitrile; gradient conditions, linear gradient of solvent B (5-45\%, 0-40min), then 100\% (40-50 min), and then retention of $100 \%$ solvent B (50-55 min); detection wavelength, 268, 280, 300, and $428 \mathrm{~nm}$. Produced purpurogallins were identified by comparing retention times and UV-VIS spectra of specific peaks with the authentic samples synthesized as stated above.

Pyrogallols and purpurogallins in the reaction solutions were quantified via the external standard method, using the following equations. For pyrogallol, $y=26,747 x-$ 
1,813 (where $\mathrm{y}=$ peak area at $268 \mathrm{~nm}$, and $\mathrm{x}=$ amount of pyrogallol, ranging $0.25-5$

nmol). For 4-methylpyrrogallol, $y=50,629 x-4$ (where $y=$ peak area at $268 \mathrm{~nm}$, and $x$ $=$ amount of 4-methylpyrogallol, ranging $0.04-10 \mathrm{nmol})$. For 5-methylpyrrogallol, $\mathrm{y}=$ $39,236 x+767$ (where $y=$ peak area at $268 \mathrm{~nm}$, and $\mathrm{x}=$ amount of 5-methylpyrogallol, ranging, $0.04-10 \mathrm{nmol}$ ). For purpurogallin, $\mathrm{y}=844,204 \mathrm{x}+535$ (where $\mathrm{y}=$ peak area at $300 \mathrm{~nm}$, and $\mathrm{x}=$ amount of purpurogallin, ranging, 0.005-0.1 nmol). For 1,7-dimethylpurpurogallin, $y=1,307,266 x+8,831$ (where $y=$ peak area at $300 \mathrm{~nm}$, and $\mathrm{x}=$ amount of 1,7-dimethylpurpurogallin, ranging, $0.004-1 \mathrm{nmol})$.

Additional $10 \mu \mathrm{L}$ aliquots were taken from the reaction solutions at the same time intervals as were used for the $\mathrm{XO}$ inhibition assay. The aliquots were assayed immediately using the same procedure as described above (in $\mathrm{pH} 7.4$ solution).

\subsection{Kinetic studies of XO inhibition}

These assays were carried out in various concentrations of xanthine (50-200 $\mu \mathrm{mol} \mathrm{L}{ }^{-1}$ ), with or without pyrogallol or purpurogallin, under conditions of no pre-incubation for the inhibitors (to prevent their degradation). Uric acid production was measured using the procedure described previously in the assay for XO inhibition, and 
reaction velocity was estimated by measuring uric acid concentration at $10 \mathrm{~min}$ after the start of the reaction. Lineweaver-Burk plotting was applied to determine the type of inhibition carried out by each inhibitor of XO activity.

\subsection{Molecular docking simulations}

Flexible-ligand molecular docking simulations were performed using the

AutoDock Vina software application (v. 1.1.2; open-source). The crystal structure of the complex formed by bovine milk xanthine oxidase (XO) with salicylic acid (Protein Data Bank entry 1FIQ, resolution = 2.5 $\mathrm{A}$ ) was obtained from the Protein Data Bank Japan (PDBj) database, and was prepared for docking using MGL Tools (v. 1.5.6.56; Scripps Research Institute, La Jolla, CA, USA). All water molecules and the ligand were removed, and hydrogens and Gasteiger partial charges were added. Three $30 \times 30 \times 30$ grid boxes were positioned at three centres of the flexible parts of the complex $\left(\mathrm{x}_{1}=\right.$ $26.79, \mathrm{y}_{1}=-9.95, \mathrm{z}_{1}=112.75 ; \mathrm{x}_{2}=19.42, \mathrm{y}_{2}=32.14, \mathrm{z}_{2}=100.72 ;$ and $\mathrm{x}_{3}=27.04, \mathrm{y}_{3}=$ $51.98, \mathrm{z}_{3}=100.72$ ) with grid spacing of $1.00 \AA$, to cover the active site of XO molecule. The exhaustiveness parameter was set to 100. The ligand structure was created using the Chem3D Ultra software package (v. 13.0.0; PerkinElmer, MA, USA) with 3D structure 
optimization by MM2 add-in software. The visualization of the enzyme-ligand interaction for the molecular configuration with the lowest binding energy (the highest stability of the complex) was prepared using Pymol (v. 1.7.6.0; open-source, distributed by Schördinger). Detailed ligand-enzyme interactions were analysed using LigPlot+ (v.1.4; open-source, distributed by the European Bioinformatics Institute, Hinxton, UK).

\section{Results and discussion}

In a previous study, we concluded that pyrogallol was the main contributor to the XO-inhibitory activity of roasted coffee; however, in the current investigation, we found that the inhibitory activity of pyrogallol varied, depending on the duration of incubation time in the XO inhibition assay. Most assay of XO inhibition have been carried out under alkaline conditions, such as $\mathrm{pH} 7.8$ or higher, because XO's catalytic activity is higher under the alkaline conditions [16]. It should be noted that, in an oxygen atmosphere, some polyphenols are unstable in such alkaline conditions, due to redox reactions. Figure 1A shows the stability of pyrogallol when in solutions of various $\mathrm{pH}$ for $10 \mathrm{~min}$ at $37^{\circ} \mathrm{C}$, which is the same reaction period of $\mathrm{XO}$ inhibition assay we employed. These results revealed that pyrogallol is stable at $\mathrm{pH} 5-6.5$, but unstable at 
$\mathrm{pH}>6.5$. Figure 1B shows $\mathrm{XO}$ activity in the presence and absence of inhibitors (pyrogallol and allopurinol) at identical $\mathrm{pH}$ conditions. XO activity decreased with the decreasing $\mathrm{pH}$ of the solution, and the XO-inhibitory activity (estimated from calculated percent inhibition) of pyrogallol almost disappeared in solutions with $\mathrm{pH}<6.5$. In contrast, allopurinol, a reference XO inhibitor, retained inhibitory activity under the identical $\mathrm{pH}$ conditions. These results indicated that some of pyrogallol's degraded products, which might be produced in solutions where $\mathrm{pH}>6.5$ could play roles in enhancing XO-inhibitory activity. Figure 2 shows the HPLC analytical profile of pyrogallol when in $\mathrm{pH} 7.4$ solution at $37^{\circ} \mathrm{C}$ for $0.5 \mathrm{~h}$. This is a typical physiological $\mathrm{pH}$, and the profile demonstrated that most of pyrogaloll was converted into new compound (indicated by peak 2 ). The new compound had a characteristic UV-VIS absorption pattern $(\lambda \max 280,300,368$, and $428 \mathrm{~nm})$, indicating that the peak corresponded to purpurogallin (Fig. 3). Purpurogallin is a dimeric compound derived from pyrogallol by a unique process of sequential oxidative dimerization and decarboxylation [17]. In addition to XO-inhibitory activity of pyrogallol [18], the potent XO-inhibitory activity of purpurogallin [19] has been reported: it has also been reported to have several other biological activities, such as antioxidant activity in liver, kidney and cardiovascular cells were reported [20-23]. Biological production of purpurogallin from pyrogallol has also 
been observed in human erythrocytes [24]. The identification of this new compound as purpurogallin was completed by comparing its retention time and UV-VIS spectra of synthetically prepared purpurogallin.

When we measured the XO-inhibitory activities of purpurogallin and pyrogallol at $\mathrm{pH} 7.4$, without pre-incubation (to prevent decomposition of the polyphenols), the data showed that both compounds have potent activities: for pyrogallol, $\mathrm{IC}_{50}$ was $1.6 \mu \mathrm{mol} \mathrm{L} \mathrm{L}^{-1}$; for purpurogallin, $\mathrm{IC}_{50}$ was $0.2 \mu \mathrm{mol} \mathrm{L} \mathrm{L}^{-1}$. A question arose: which compound is the primary contributor of $\mathrm{XO}$ inhibition under physiological $\mathrm{pH}$ conditions $\left(\mathrm{pH}=7.4\right.$, temperature $\left.=37^{\circ} \mathrm{C}\right)$ ? Pyrogallol is not very stable under these conditions (10 min at $\mathrm{pH} 7.4)$. Time-course measurements of XO-inhibitory activity, and concentrations of pyrogallol, and concentration of produced purpurogallin were then carried out in the $\mathrm{pH} 7.4$ conditions. The resulting data displayed in Fig. 4 showed that the initial XO-inhibitory activity was $38 \%$ inhibition when the initial concentration of pyrogallol was $24 \mu \mathrm{mol} \mathrm{L}{ }^{-1}$ of pyrogallol (the corresponding concentration in the $\mathrm{XO}$ inhibition assay solution was $1 \mu \mathrm{mol} \mathrm{L} \mathrm{L}^{-1}$ ). As the reaction proceeded, pyrogallol decreased (at a rate in accordance with a second-order reaction) until $2 \mathrm{~h}$; however the purpurogallin concentration increased during the initial $30 \mathrm{~min}$, and then decreased gradually. Additionally, XO-inhibitory activity increased around 40 min after reaction 
initiation, strongly indicating that the produced purpurogallin enhanced the XO-inhibitory activity occurring in the solution. Murakami and co-workers [25] suggested that 5-methylpyrogallol could not be converted into purpurogallin derivatives. Dürckheimer and Pauhus [26] reported that the reaction between pyrogallol and 3,4-dimethylcatechol (which is analogous to 5-methylpyrogallol) did not produce the purpurogallin structure. We measured XO-inhibitory activity of two methyl-substituted pyrogallols, 4-methylpyrogallol and 5-methylpyrogallol, and we analysed their conversion to purpurogallins, under identical reaction conditions. The resulting data are shown in Figs. 5 and 6. Figures 5A and B show the HPLC analytical data for the pH 7.4 solutions of 4-methylpyrogallol and 5-methylpyrogallol, respectively. Here, we see that only 4-methylpyogallol gave a purpurogallin-like product, a compound that had a similar UV-VIS absorption pattern ( $\lambda \max 284,308,384$, and $440 \mathrm{~nm})$ to that of purpurogallin, at the retention time of $46 \mathrm{~min}$. This purpurogallin-like compound derived from 4-methylpyrogallol was identical to 1,7-dimethylpurpurogalin, based on NMR and MS analyses (Fig. 3). It should be noted that while 4-methylpyrogallol showed weak but certain initial XO-inhibitory activity (35\% inhibition at a concentration of $10 \mu \mathrm{mol} \mathrm{L}{ }^{-1}$ ), 5-methylpyrogallol showed almost no XO-inhibitory activity at the same concentration (Fig. 6). The time-course data also showed that 
4-methylpyrogallol enhanced XO-inhibitory activity in a pattern similar to that of pyrogallol, while 5-methylpyrogallol did not enhance XO-inhibitory activity, as is shown in Figs. 6A and B. Although methyl substitution decreased the XO-inhibitory activity from an $\mathrm{IC}_{50} 1.6 \mu \mathrm{mol} \mathrm{L}{ }^{-1}$ (for the original non-substituted pyrogallol), to an $\mathrm{IC}_{50} 33.3 \mu \mathrm{mol} \mathrm{L}-1$ (for 4-methylpyrogallol), to an $\mathrm{IC}_{50}>200 \mu \mathrm{mol} \mathrm{L}{ }^{-1}$ (for 5-methylpyrogallol) (Table 1), the purpurogallin-like compound (1,7-dimethylpurpurogallin) derived from 4-methylpyrogallol enhanced XO-inhibitory effects with an $\mathrm{IC}_{50}$ of $8.0 \mu \mathrm{mol} \mathrm{L}{ }^{-1}$.

Next, kinetic analyses of $\mathrm{XO}$ inhibition were performed using various concentrations of the substrate, xanthine, in the presence of the XO inhibitors (pyrogallol and purpurogallin). The data are illustrated in Fig. 7 as Lineweaver-Burk plots. From these plots, and under the conditions employed, the $K m$ value for xanthine was calculated to be $6.7 \mu \mathrm{mol} \mathrm{L}$. The plots also showed that the inhibition mechanism of pyrogallol and purpurogallin were of the same mixed type, this indicated that the molecular interactions between the XO-inhibitors and $\mathrm{XO}$ itself may occur in the active site of XO, including the region around the molybdopterin cofactor (the catalytic site of $\mathrm{XO)}[27]$.

Recently, developed molecular docking software emerged as a useful tool for 
theoretical drug design. Computer-based simulations of small molecule (ligand)-protein interactions, including interactions occurring between enzymes and their inhibitors provide insight into the stability of such complex and also provide direct simulated images of the interaction sites by enabling visualizations of simulation results. Although many molecular docking software applications are now available [28], we chose AutoDock Vina (developed and provided by Trott and Olson) [29], because it has greater and more accurate calculating abilities; thus, we used it to estimate the contributions of pyrogallol itself and its derivative, purpurogallin, to the potent XO-inhibitory activities attributed to pyrogallol. All of our docking simulations were of interaction between a molecule of interest and the active site of $\mathrm{XO}$; the results are shown in Table 1 and Fig. 8. The docking simulation for xanthine is shown in the left-top panel of Fig. 8. It is well documented that the oxidation of xanthine into uric acid begins with the oxygenation of the carbon in the 8-positon by molybdenum (VI) ion in the molybdopterin cofactor of XO [30]. Although the predicted binding energy for this site and xanthine is not very low $\left(-7.1 \mathrm{kcal} \mathrm{mol}^{-1}\right)$ (Table 1$)$, the most stable binding conformation for xanthine shows that the carbon in the 8-positon sits near (within $1.9 \AA$ ) the oxygen that is bound to the molybdenum atom, which indicated that our simulation using AutoDock Vina worked quite accurately. The other panels of Fig. 8 
show the most likely docking configurations (as estimated by having the lowest software-predicted binding energies as summarized in Table 1) of each inhibitor around the molybdopterin catalytic site of XO. These images revealed that two purpurogallins bind more closely to the molybdenum of the XO than do the pyrogallols. Figure 9 shows the interactions amino acid residues of the XO active site with the bound pyrogallol and purpurogalin molecules; these interactions were deduced by LigPlot+, using a previously reported protocol [31]. Specifically, docked purpurogallin appeared to be stabilized at $-11.0 \mathrm{kcal} \mathrm{mol}^{-1}$, possibly by two hydrogen bonds with $\operatorname{Arg} 880$ (2.79 and $2.93 \AA$ ), three hydrogen bonds with Thr1010 (2.70, 2.83, and 3.00 $)$ ), and one hydrogen bond with Val1011 (2.93 $\AA$ ); docking stabilization may have also been enhanced by hydrophobic interactions with the hydrophobic moieties of Glu802, Leu873, Phe914, Phe1009, Leu1014, Ala1078, Ala1079, Glu1261, and Mte1333 (molybdopterin) (Fig. 9 A). In contrast, docked pyrogallol speared to have lower stability (predicted binding energy is $-7.6 \mathrm{kcal} \mathrm{mol}^{-1}$ ) derived from interactions with polar amino acids through hydrogen bonds [specifically, three with $\operatorname{Arg} 880(2.99,2.93$, and $3.31 \AA$ ) and four with $\operatorname{Thr} 1010(2.79,2.93,2.97$, and $3.48 \AA)]$ and with interactions with fewer hydrophilic amino acids (Glu802, Phe914, Phe1009, and Ala1079) (Fig. 9B). Additional AutoDock simulations provided the next lower binding energies for 
1,7-dimetylpurpurogallin in the FAD and molybdopterin regions of $\mathrm{XO}$, which were $-9.2 \mathrm{kcal} \mathrm{mol}^{-1}$ and $-9.1 \mathrm{kcal} \mathrm{mol}^{-1}$, respectively (Table 1). The XO-inhibitory efficiencies of both purpurogallins $\left(\mathrm{IC}_{50}=0.2 \mu \mathrm{mol} \mathrm{L}{ }^{-1}\right.$ for purpurogallin; $\mathrm{IC}_{50}=8.0$ $\mu \mathrm{mol} \mathrm{L}^{-1}$ for 1,7-dimethylpurpurogallin) can be accounted by their affinity to the $\mathrm{XO}$ molecule. Although 4- and 5-methylpyrogallols showed moderate binding energies (-8.3 $\mathrm{kcal} \mathrm{mol}^{-1}$ and $-8.0 \mathrm{kcal} \mathrm{mol}^{-1}$, respectively) in the simulation studies, the $\mathrm{XO}$ inhibitory activities of these compounds $\left(\mathrm{IC}_{50}=33.3 \mu \mathrm{mol} \mathrm{L}{ }^{-1}\right.$ for 4-methylpyrogallol and $\mathrm{IC}_{50}>$ $200 \mu \mathrm{mol} \mathrm{L}{ }^{-1}$ for 5-methylpyrogallol) were observed to be much lower than those of two purpurogallins, and also much lower than that of pyrogallol ( $\left.\mathrm{IC}_{50} 1.6 \mu \mathrm{mol} \mathrm{L}{ }^{-1}\right)($ Table 1). XO contains many hydrophobic amino acid residues, such as phenylalanine and leucine, on the surface of the catalytic site. Methyl substitution enhances the hydrophobicity of the mother compounds; therefore, it can raise their binding affinities for XO by increasing hydrophobic interactions, unless steric hindrance becomes an issue. The relatively higher binding energies of 4-methylpyrogallol and 5-methylpyrogallol compared to that of pyrogallol could be explained by their enhanced hydrophobicity. However, their higher $\mathrm{IC}_{50}$ values (which translates to have lower inhibitory activity), especially that of 5-methylpyrogallol, could not be explained by binding affinity. We noted that, under alkaline conditions, no substitution of the carbon 
in the 5-position is necessary to produce the purpurogallin structure; the final step for purpurogallin formation requires deprotonation and subsequent enolisation at the 5-position of pyrogallol [32]. Therefore, 5-methylpyrogallol could not accommodate any corresponding compound bearing purpurogallin structure, and it showed no XO-inhibitory activity as a result.

No study has yet reported on the plasma concentration of purpurogallin after its administration. However, some biological activities of orally administrated purpurogallin have been observed in laboratory animals (Mammalia) [33-35]. The results of those studies indicate that purpurogallin is absorbed in mammalian bodies through the gastrointestinal track and then manifest its activities. Recently, the bioavailability of various polyphenols, including those in coffee (ca.150 mg polyphenols in a cup of coffee), was well investigated [36-39]. The results showed that the maximum concentrations $(C \max )$ of polyphenols in plasma are not high, but are observed in the range of $\mathrm{nmol} \mathrm{L} \mathrm{L}^{-1}$ to low- $\mu$ mol $\mathrm{L}^{-1}[40]$. An effective plasma concentration of purpurogallin, which can be estimated from its $\mathrm{IC}_{50}$ value $(0.2 \mu \mathrm{mol}$ $\mathrm{L}^{-1}$ ), is achievable by ingesting purpurogallin-containing foods. Although freshly brewed coffee does not contain purpurogallin, purpurogallin can be formed in the small intestine from pyrogallol present in drinkable coffee, because the small intestine has an 
alkaline environment. The amount of pyrogallol in roasted coffee was reported to be higher $(4 \sim 8 \mu \mathrm{g} / \mathrm{g}$ liquid coffee) than that in other liquid beverages such as beer $(0.05 \sim 0.3 \mu \mathrm{g} / \mathrm{g}$ beer) [41]. Pyrogallol was also observed in mammalian plasma as a catabolite of some polyphenols of black tea or berries $[42,43]$. The half-life of pyrogallol in plasma was measured to be within $1 \mathrm{~h} \mathrm{[44].} \mathrm{This} \mathrm{indicates} \mathrm{that} \mathrm{pyrogallol}$ is found in an unstable form in the plasma $(\mathrm{pH} \mathrm{7.4)} \mathrm{and} \mathrm{is} \mathrm{rapidly} \mathrm{sulphated} \mathrm{[43]} \mathrm{or,}$ possibly, converted to purpurogallin, as observed in the present in vitro investigation. The mechanisms of action of not only pyrogallol but also purpurogallin in the living body are still unclear. Further studies are necessary to understand the bioavailability and mechanism of in vivo XO inhibitory activity of both compounds as well as their source, coffee.

In conclusion, the conversion of pyrogallol into purpurogallin in alkaline conditions (including at the physiological model condition of $\mathrm{pH} 7.4$ ) should be considered an important step in the mechanism of the potent XO-inhibition effects shown by pyrogallol and probably by pyrogallol-contained roasted coffee, -regardless of whether pyrogallol itself is responsible for the XO-inhibitory activity. 


\section{Source of funding}

This work was supported by JSPS Kakenhi [Grant Numbers JP15H02892 to T.

M. and JP16J03454 to S. H.] and a collaborative research fund between AGF and Osaka

City University.

Acknowledgment

We thank Dr. Shigeyoshi Fujii of Ajinomoto General Foods Inc. (AGF) for the helpful discussion. S.H. thanks JSPS for a DC1 research fellowship.

\section{Appendix A. Supplementary material}

Supplementary data (Fig. S1) associated with this article can be found in the online. 


\section{References}

[1] H. K. Choi, D. B. Mount, A. M. Reginato, Pathogenesis of gout, Ann. Intern. Med. 143 (2005) 499-516.

[2] K. G. Saag, H. K. Choi, Epidemiology, risk factors, and lifestyle modifications for gout, Arthritis Res, Ther. 8 (2006) S2.

[3] K. Sugamura, J. F. Keaney Jr., Reactive oxygen species in cardiovascular disease, Free Radic. Biol. Med. 51 (2011) 978-992.

[4] M. P. Keith, W. R. Gilliland, Updates in the management of gout, Am. J. Med. 120 (2007) 221-224.

[5] L. Beara-Lasic, M. H. Pillinger, D. S. Goldfarb, Advances in the management of gout: Critical appraisal of febuxostat in the control of hyperuricemia. Int. J. Nephrol. Renovasc. Dis. 3 (2010) 1-10.

[6] C. Spanou, A. S. Veskoukis, T. Kerasioti, M. Kontou, A. Angelis, N. Aligiannis, A.-L. Skaltsounis, D. Kouretas, Flavonoid glycosides isolated from unique legume plant extracts as novel inhibitors of xanthine oxidase, Plos One, 7 (2012) 1-7.

[7] H. K. Choi, W. Willett, G. Curhan, Coffee consumption and risk of incident gout in men: A prospective study, Arthritis Rheum. 56 (2007) 2049-2055. 
[8] H. K. Choi, G. Curhan, Coffee, tea, and caffeine consumption and serum uric acid level: the third national health and nutrition examination survey, Arthritis Rheum. 57 (2007) 816-821.

[9] N. M. Pharm, D. Yoshida, M. Morita, G. Yin, K. Toyomura, K. Ohnaka, R. Takayanagi, S. Kono, The relation of coffee consumption to serum uric acid in Japanese men and women aged 49-76 years, J. Nutri. Metabl. 2010 (2010) 1-7.

[10] S. Honda, Y. Miura, A. Masuda, T. Masuda, Identification of crypto- and neo-chlorogenic lactones as potent xanthine oxidase inhibitors in roasted coffee beans, Biosci. Biotechnol. Biochem. 78 (2014) 2110-2116.

[11] S. Honda, T. Masuda, Identification of pyrogallol in the ethyl acetate-soluble part of coffee as the main contributor to its xanthine oxidase inhibitory activity, J. Agric. Food Chem. 64 (2016) 7743-7749.

[12] R. P. Pulido, L. Bravo, F. Saura-Calixto, Antioxidant activity of dietary polyphenols as determined by a modified ferric reducing/antioxidant power assay, $\mathrm{J}$. Agric. Food Chem. 48 (2000) 3396-3402.

[13] K. Lemańska, H. Szymusiak, B. Tyrakowska, R. Zieliński, A. E. M. F. Soffers, I. M. C. M. Rietjens, The influence of $\mathrm{pH}$ on antioxidant properties and the mechanism of antioxidant action of hydroxyflavones, Free Radic. Biol. Med. 31 (2001) 869-881. 
[14] T. Masuda, Y. Shingai, C. Takahashi, M. Inai, Y. Miura, S. Honda, A. Masuda, Identification of a potent xanthine oxidase inhibitor from oxidation of caffeic acid, Free Radic. Biol. Med. 69 (2014) 300-307.

[15] T. W. Evans, W. M. Dehn, Organic oxidation by iodic acid, J. Am. Chem. Soc. 52 (1930) 3647-3649.

[16] L. Greenlee, P. Handler, Xanthine oxidase VI. Influence of pH on substrate specificity, J. Biol. Chem. 236 (1964) 1090-1095.

[17] J. A. Barltrop, J. S. Nicholson, The oxidation products of phenolics. Part I. The structure of purpurogallin, J. Chem. Soc. (1948) 116-120.

[18] S. J. Gray, R. Z. Felsher, Studies on the inhibition of xanthine oxidase, Exp. Biol. Med. 59 (1945) 287-289.

[19] S.-Y. Sheu, C.-H. Lai, H.-C. Chiang, Inhibition of xanthine oxidase by purpurogallin and silimarin group, Anticancer Res. 18 (1998) 263-268.

[20] Y. Inamori, C. Mura, E. Saijima, M. Katagiri, Y. Okamoto, H. Tanaka, Y. Sakagami, H. Tsujibo, Biological activity of purpurogallin, Biosci. Biotechnol. Biochem. 61 (1997) 890-892.

[21] T.-W. Wu, L.-H. Zeng, J. Wu, D. Carey, Purpurogallin-a natural and effective hepatoprotector in vitro and in vivo, Biochem. Cell. Biol. 69 (1991) 747-750. 
[22] L.-H. Zeng, T.-W. Wu, Purpurogallin is a more powerful protector of kidney cells than trolox and allopurinol, Biochem. Cell. Biol. 70 (1992) 684-690.

[23] T.-W. Wu, J. Wu, D. Carey, L.-H. Zeng, Purpurogallin protects both ventricular myocytes and aortic endothelial cells of rats against oxyradical damage, Biochem. Cell. Biol. 70 (1992) 803-809.

[24] K. Miyazaki, S. Arai, T. Iwamoto, M. Takasaki, A. Tomoda, Metabolism of pyrogallol to purpurogallin by human erythrocytic hemoglobin. Tohoku J. Exp. Med. 203 (2004) 319-330.

[25] M. Murakami, K. Suzuki, E. Mishima, Synthesis of the purpurogallin type compounds. I, Nippon Kagaku Zasshi, 75 (1954) 620-622.

[26] W. Dürckheimer, E. F. Paulus, Mechanism of purpurogallin formation: An adduct from 3-hydroxy-o-benzoquinone and 4,5-dimethyl-o-benzoquinone, Angew. Chem. Int. Ed. 24 (1985) 224-225.

[27] Z.-P. Xiao, Z.-Y. Peng, J.-J. Dong, R.-C. Deng, X.-D. Wang, H. Puyang, P. Yang, J. He, Y.-F. Wang, M. Zhu, X.-C. Peng, W.-X. Peng, H.-L. Zhu, Synthesis, molecular docking and kinetic properties of $\beta$-hydroxy- $\beta$-phenylpropionyl-hydroxamic acids as Helicobacter pylori urease inhibitors, Euro. J. Med. Chem. 68 (2013) 212-221.

[28] M. W. Chang, C. Ayeni, S. Breuer, B. E. Torbett, Virtual screening for HIV protease 
inhibitors: A comparison of AutoDock 4 and Vina, Plos One 5 (2010) e11955.

[29] O. Trott, A. J. Olson, Autodock Vina: improving the speed and accuracy of docking with a new scoring function, efficient optimization, and multithreading, J. Comput. Chem. 31 (2010) 455-461.

[30] H. Cao, J. M. Pauff, R. Hille, Substrate orientation and catalytic specificity in the action of xanthine oxidase, the sequential hydroxylation of hypoxanthine to uric acid, J. Biol. Chem. 36 (2010) 28044-28053.

[31] R. A. Laskowski, M. B. Swindells, LigPlot+: multiple ligand-protein interaction diagrams for drug discovery, J. Chem. Inf. Model. 51 (2011) 2778-2786.

[32] A. Critchlow, E. Haslam, R. D. Haworth, P. B. Tinker, N. M. Waldron, The oxidation of some pyrogallol and purpurogallin derivatives, Tetrahedron 23 (1967) $2829-2847$.

[33] C.-Z. Chang, C.-L. Lin, S.-C. Wu, A.-L. Kwan, Purpurogallin, a natural phenol, attenuates high-mobility group box 1 in subarachnoid hemorrhage induced vasospasm in a rat model, Int. J. Vascular Med. 2014 (2014) 1-9.

[34] J. Szabó, G. Bruckner, I. Medeveczky, E. Kósa, A. Balogh, Ethanol’s effect on rat pituitary adrenal axis is prevented by purine metabolic pathway inhibitor, Exp. Biol. Med. 220 (1999) 112-118. 
[35] K. Prasad, S. V. Mantha, J. Lalra, R. Kapoor, B. R. C. Kamalajan, Purpurogallin in their prevention of hyperchlesterolemic atherosclerosis, Int. J. Angiol. 6 (1997) $157-166$.

[36] D. D. Rio, A. Rodriguez-Malteos, J. P. E. Spencer, M. Tognolini, G. Borges, A. Crozier, Dietary (Poly)phenolics in human health: Structures, bioavailability, and evidence of protective effects against chronic diseases, Antioxid. Redox Signal. 18 (2013) 1818-1892.

[37] F. Natella, M. Nardini, I. Giannetti, C. Dattilo, C. Scaccini, Coffee drinking influences plasma antioxidant capacity in humans, J. Agric. Food Chem. 50 (2002) $6211-6216$.

[38] M. Nardini, E. Cirillo, F. Natella, C. Scaccini, Absorption of phenolic acids in humans after coffee consumption, J. Agric. Food Chem. 50 (2002) 5735-5741.

[39] A. Stalmach, W. Mullen, D. Barron, K. Uchida, T. Yokota, C. Cavin, H. Steiling, G. Williamson, A. Crozier, Metabolite profiling of hydroxycinnamate derivatives in plasma and urine after the ingestion of coffee by humans: identification of biomarkers of coffee consumption, Drug Metab Dispos. 37 (2009) 1749-1758.

[40] G. Williamson, F. Dionisi, M. Renouf, Flavanols from green tea and phenolic acids from coffee: Critical quantitative evaluation of the pharmacokinetic data in humans 
after consumption of single doses of beverages, Mol. Nutr. Food Res. 55 (2011) $1-10$.

[41] R. Lang, C. Mueller, T. Hofmann, Development of a stable isotope dilution analysis with liquid chromatography-tandem mass spectrometry detection for the quantitative analysis of di- and trihydroxybenzenes in foods and model systems, J. Agric. Food Chem. 54 (2006) 5755-5762.

[42] P. C. Van der Pijl, M. Foltz, N. D. Glube, S. Peters, G. S. M. J. E. Buchateau, Pharmacokinetics of black tea-derived phenolic acids in plasma, J. Funct. Foods 17 (2015) 667-675.

[42] R. P. Feliciano, G. Istas, C. Heiss, A. Rodrigues-Mateos, Plasma and urinary phenolic profiles after acute and repetitive intake of wild blueberry, Molecules 21 (2016) 1120 .

[43] P. N. Palma, L. E. Kiss, P. Soares-Da-Silva, Catechol-O-methyl-transferase inhibitors: Present problems and relevance of the new ones, in: A. Martinez, C. Gil (Eds.), Emerging Drugs and Targets for Parkinson's Disease, RSC Drug Discovery, Series No. 34, Chapter 4, Royal Society of Chemistry, London, 2013, pp. 83-109. 


\section{Table . 1}

XO-Inhibitory activities and the predicted lowest binding energies for pyrogallols and purpurogallins.

\begin{tabular}{lcc}
\hline Compound & $\begin{array}{c}\mathrm{IC}_{50} \text { for XO Activity } \\
\left.(\mu \mathrm{mol} \mathrm{L})^{-1}\right)\end{array}$ & $\begin{array}{c}\text { Predicted Lowest and } \\
\text { Second Lowest Binding } \\
\text { Energies (AutoDock Vina } \\
\end{array}$ \\
& $\begin{array}{c}\text { Score) } \\
\left(\mathrm{kcal} \mathrm{mol}^{-1}\right)\end{array}$ \\
\hline Pyrogallol (1) & 1.6 & $-7.6^{\mathrm{a}},-7.2^{\mathrm{a}}$ \\
4-Methylpyrogallol (3) & 33.3 & $-8.3^{\mathrm{a}},-7.9^{\mathrm{a}}$ \\
5-Methylpyrogallol (4) & $>200$ & $-8.0^{\mathrm{a}},-7.9^{\mathrm{a}}$ \\
Purpurogallin (2) & 0.2 & $-11.0^{\mathrm{a}},-10.0^{\mathrm{a}}$ \\
1,7-Dimethylpurpurogallin (5) & 8.0 & $-9.2^{\mathrm{b}},-9.1^{\mathrm{a}}$ \\
\hline
\end{tabular}

The lowest binding energy of xanthine is predicted to be $-7.1 \mathrm{kcal} \mathrm{mol}^{-1}$.

${ }^{a}$ Binding energy of each inhibitor at the molybdopterin region (the catalytic site) of XO.

${ }^{\mathrm{b}}$ Binding energy of each inhibitor at the FAD region of XO. (Figure S1) 
Figure Captions

Fig. 1. Stability of pyrogallol in various $\mathrm{pH}$ solutions (A), and $\mathrm{XO}$ activity in the presence or absence of pyrogallol $\left(1.2 \mu \mathrm{mol} \mathrm{L} \mathrm{L}^{-1}\right)$ and allopurinol $\left(1.0 \mu \mathrm{mol} \mathrm{L} \mathrm{L}^{-1}\right)$ under the same $\mathrm{pH}$ conditions (B).

Data are expressed as the mean $\pm \operatorname{SD}(n=3)$.

Fig. 2. HPLC analytical data for the reaction products from pyrogallol in $\mathrm{pH} 7.4$ solution at $37^{\circ} \mathrm{C}$ for $30 \mathrm{~min}$.

HPLC conditions: column, Cosmosil 5C18-AR-II $(250 \times 4.6 \mathrm{~mm}$ i.d. $)$; solvent A: $\left[0.1 \%\right.$ phosphoric acid in water], solvent $\mathrm{B}, \mathrm{CH}_{3} \mathrm{CN}$; gradient conditions [percent of solvent B (time)], 5\% (0 min), 45\% (40 $\mathrm{min}), 100 \%$ (50-55 min); flow rate, $1.0 \mathrm{~mL}$ $\min ^{-1}$

Fig. 3. Chemical structures of pyrogallols (1, 3, and 4) and purpurogallins (2 and 5).

Fig. 4. Time-course analytical data for pyrogallol and subsequently produced purpurogalin in $\mathrm{pH} 7.4$ solution, and XO-inhibitory activity of the solution. 
Concentration values for each compound are expressed as the mean obtained from two independent experiments, and inhibition data are expressed as the mean \pm $\mathrm{SD}(\mathrm{n}=3)$. Inhibitor concentrations in XO inhibition assay were regarded to be 1.0 $\mu \mathrm{mol} \mathrm{L} \mathrm{L}^{-1}$, based on the initial concentration of pyrogallol.

Fig. 5. HPLC analytical data for the reaction products from (A) 4-methylpyrogallol (3) and (B) 5-methylpyrogallol (4) in $\mathrm{pH} 7.4$ solution at $37^{\circ} \mathrm{C}$ for $30 \mathrm{~min}$.

HPLC conditions: column, Cosmosil 5C18-AR-II $(250 \times 4.6 \mathrm{~mm}$ i.d.); solvent A: [0.1\% phosphoric acid in water], solvent $\mathrm{B}, \mathrm{CH}_{3} \mathrm{CN}$; gradient conditions [percent of solvent B (time)], 5\% (0 min), 45\% (40 $\mathrm{min}), 100 \%$ (50-55 min); flow rate, $1.0 \mathrm{~mL}$ $\min ^{-1}$

Fig. 6. Time-course analytical data for 4-methylpyrogallol (3) and 5-methylpyrogallol (4) in $\mathrm{pH} 7.4$ solution, and the XO-inhibitory activity of the solutions.

Concentration values for each compound are expressed as the mean obtained from two independent experiments, and inhibition data are expressed as the mean \pm $\mathrm{SD}(\mathrm{n}=3)$. Inhibitor concentrations in the $\mathrm{XO}$ inhibition assay were regarded to be 10 $\mu \mathrm{mol} \mathrm{L} \mathrm{L}^{-1}$, based on the initial concentration of each methylpyrogallol. 
Fig. 7. Lineweaver-Burk plots for (A) pyrogallol and (B) purpurogallin.

The different slopes of the plots are present the experimental data corresponding to different concentrations of the inhibitors.

Fig. 8. Docking modes of xanthine, pyrogallols (1, 3, and 4), and purpurogallins (2 and 5) into the catalytic site of XO.

Fig. 9. Predicted interactions between amino acid residues belonging to the catalytic site of $\mathrm{XO}$ with (A) purpurogallin and (B) pyrogallol.

Hydrogen bonds are shown as green dotted line, and hydrophobic interactions are shown as red spoked arcs. These were automatically produced by LigPlot+. 

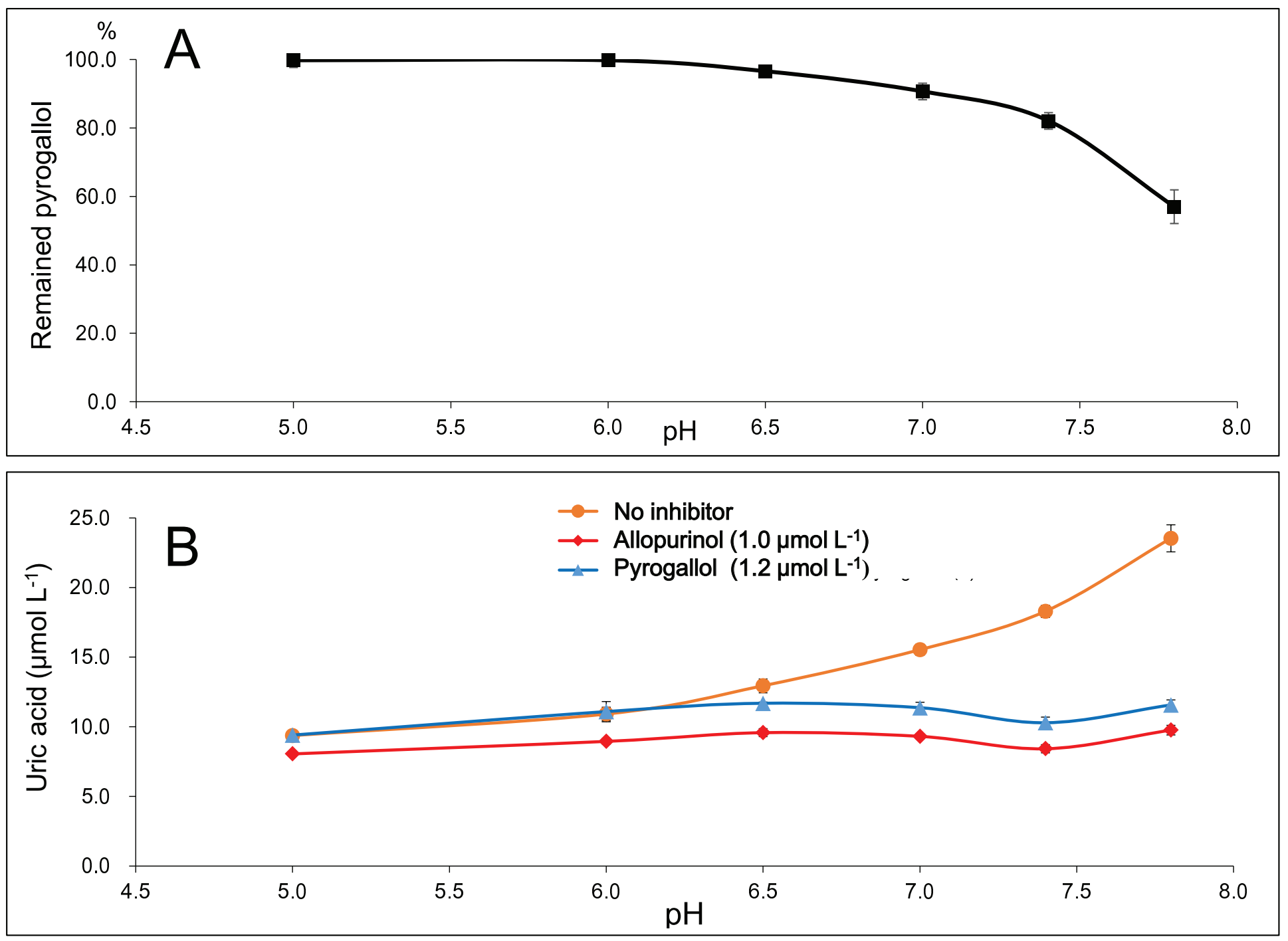

Fig. 1. 


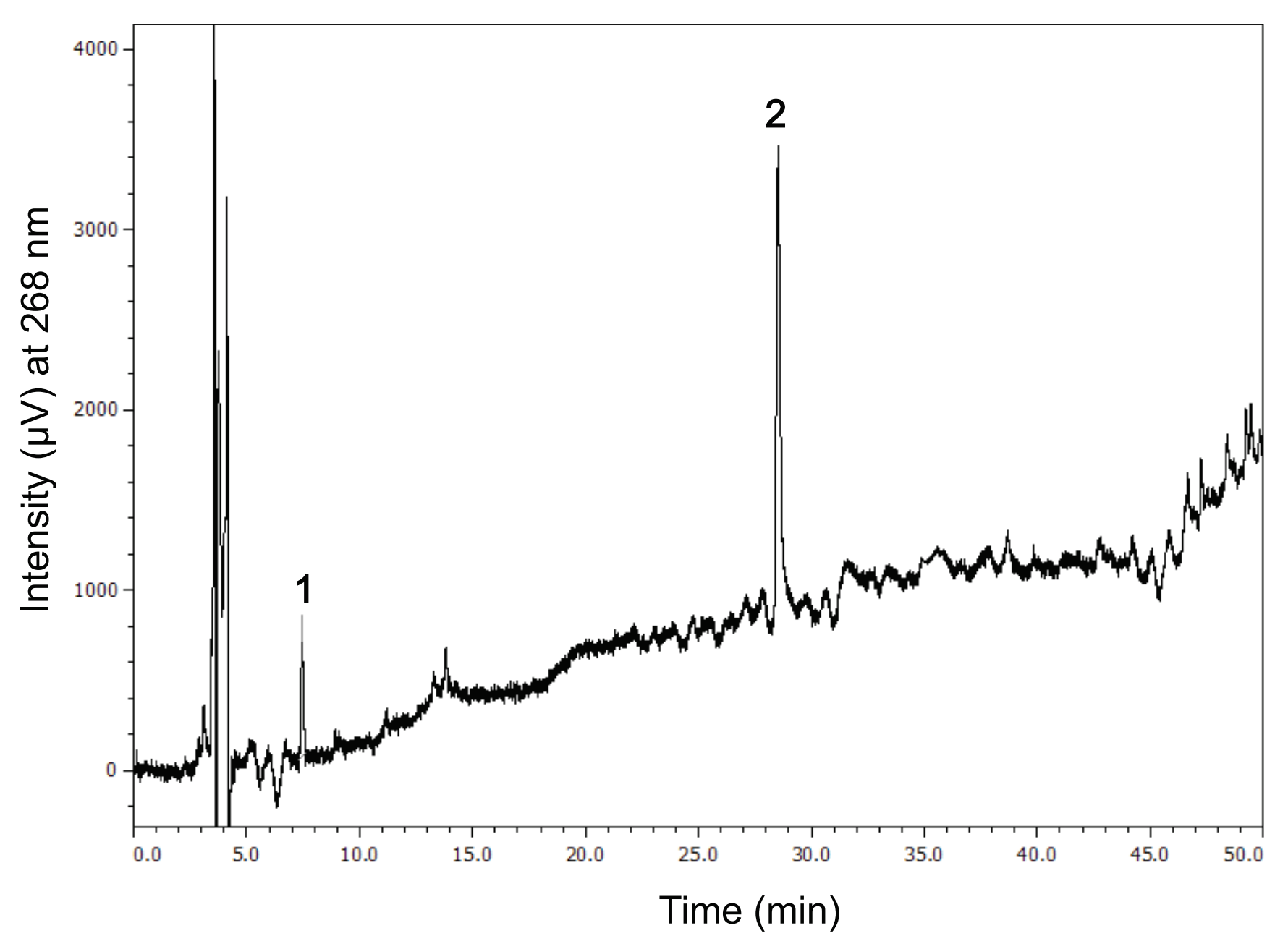

Fig. 2.

Figure 


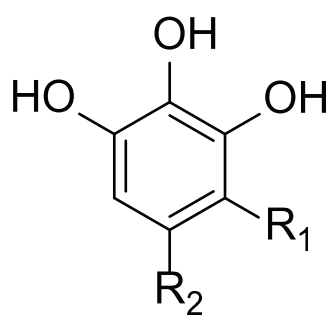

Pyrogallol (1): $\mathrm{R}_{1}, \mathrm{R}_{2}=\mathrm{H}$

4-Methylpyrogallol (3): $\mathrm{R}_{1}=\mathrm{CH}_{3}, \mathrm{R}_{2}=\mathrm{H}$

5-Methylpyrogallol (4): $\mathrm{R}_{1}=\mathrm{H}, \mathrm{R}_{2}=\mathrm{CH}_{3}$

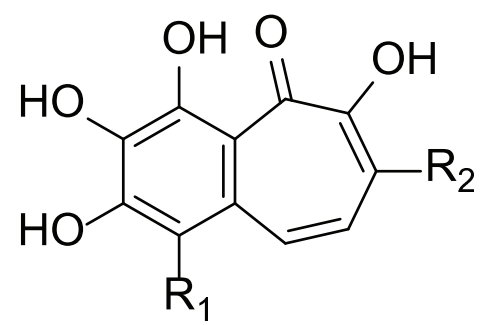

Purpurogallin (2): $\mathrm{R}_{1}, \mathrm{R}_{2}=\mathrm{H}$

1, 7-Dimethylpurpurogallin (5): $\mathrm{R}_{1}, \mathrm{R}_{2}=\mathrm{CH}_{3}$

Fig. 3 


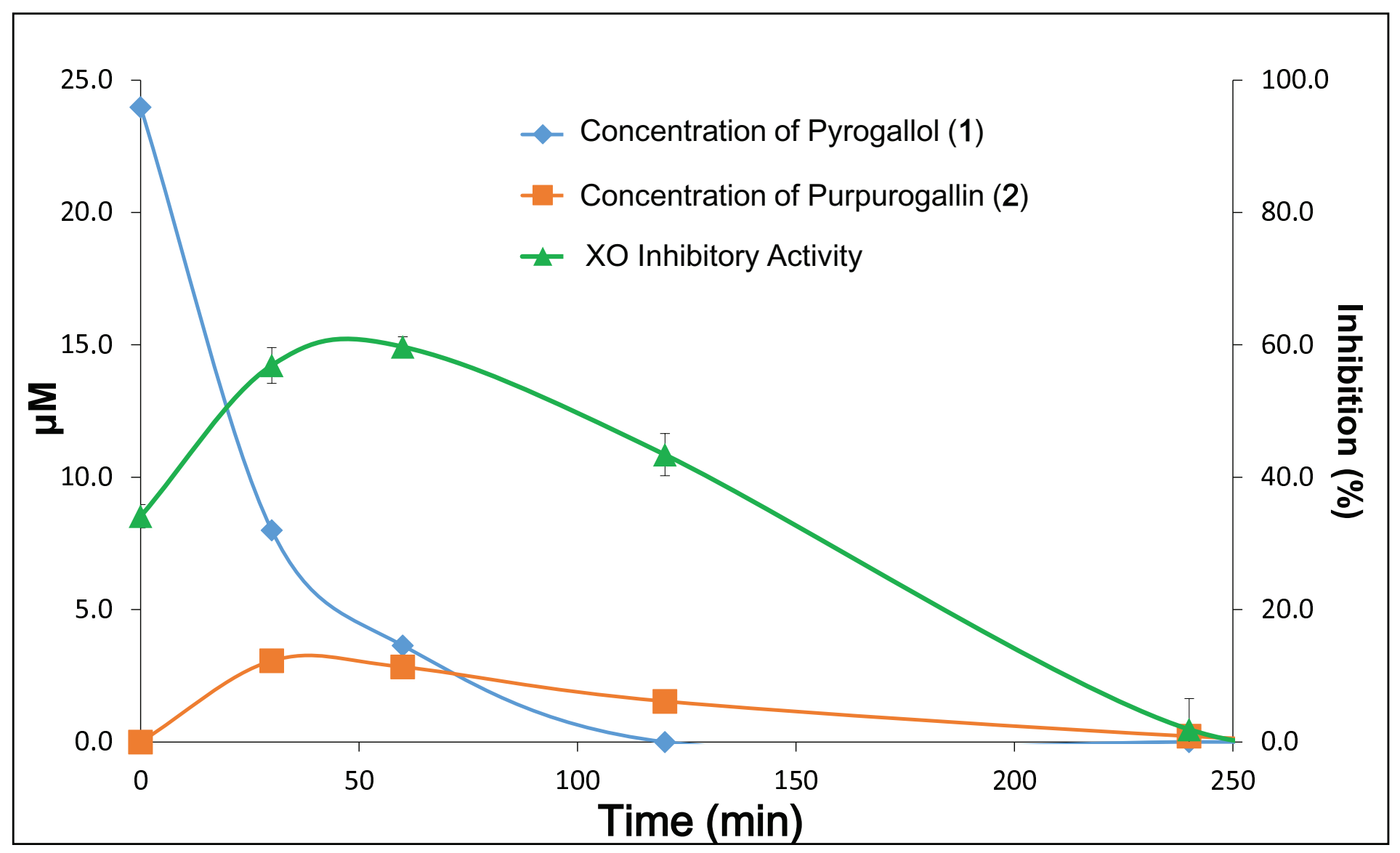

Fig. 4. 
Figure5

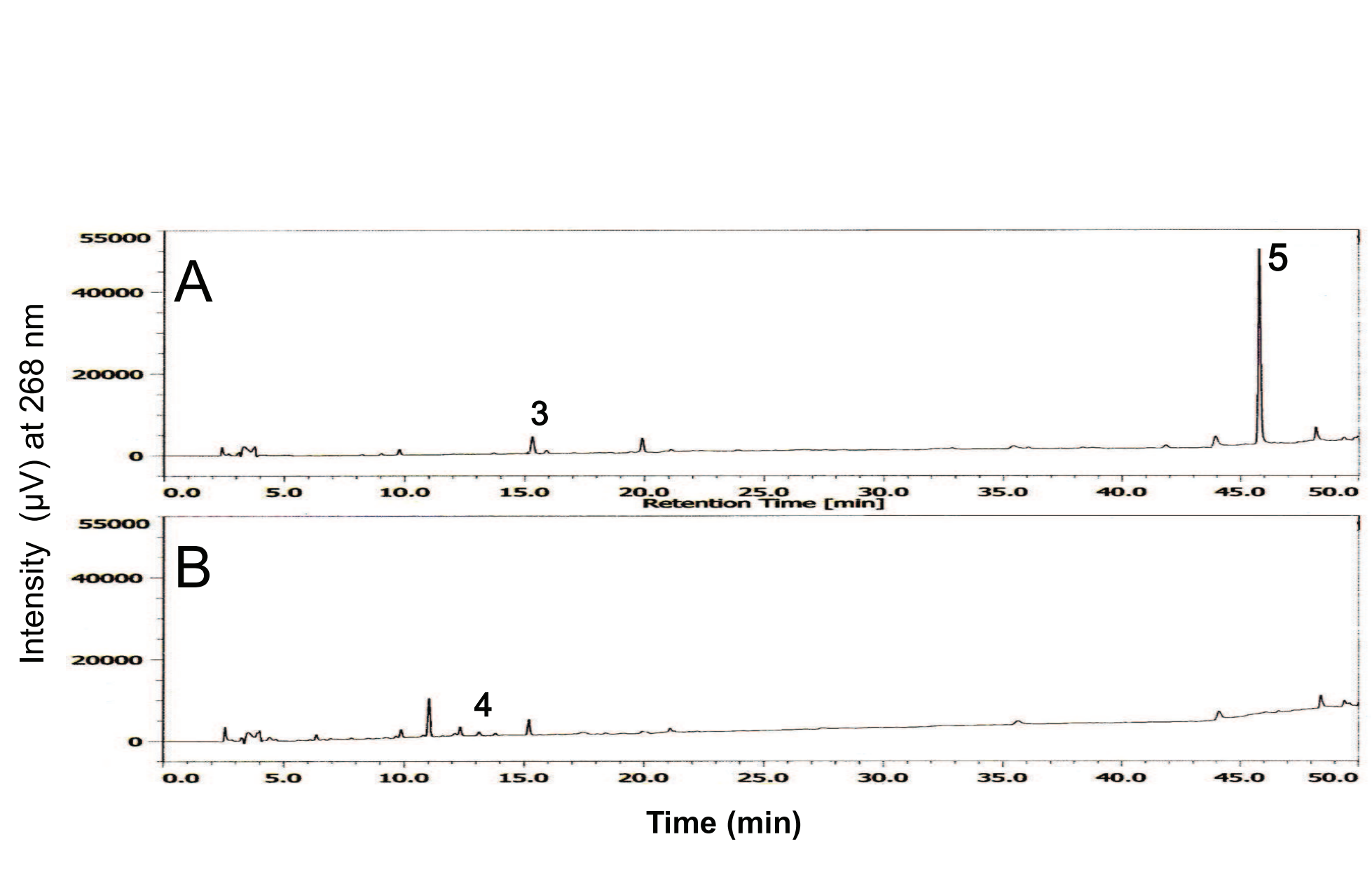

Fig.5.

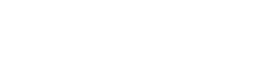

-

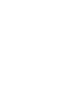
(1)

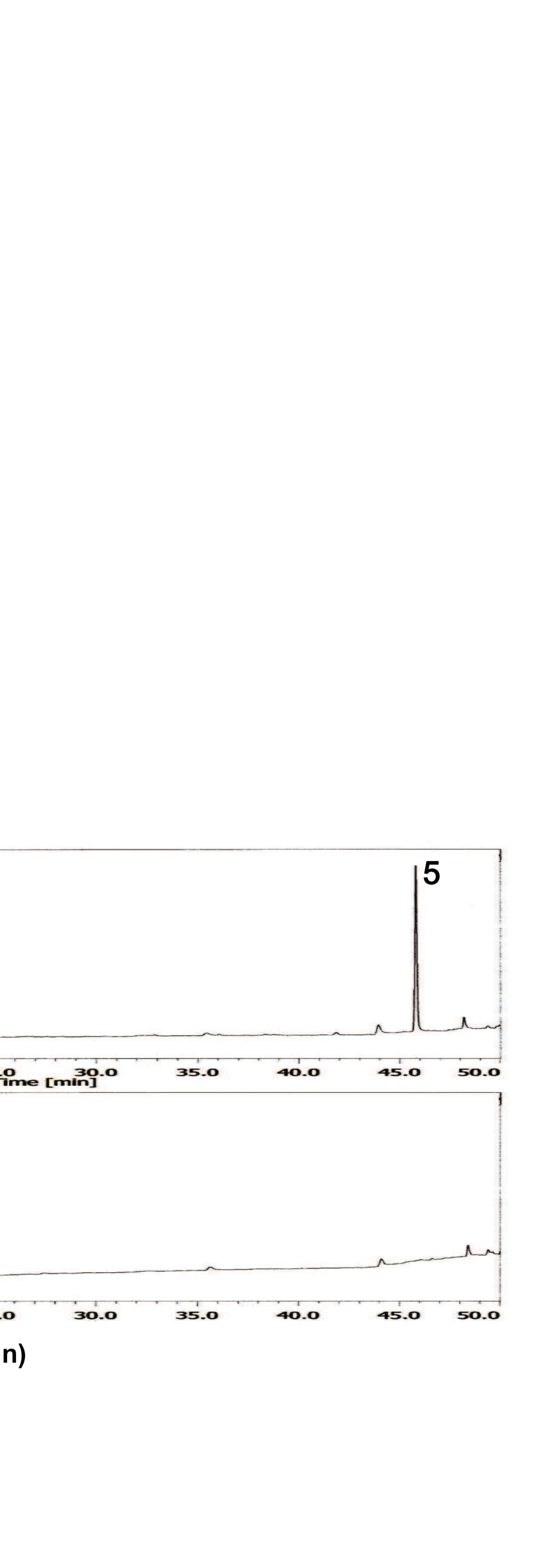




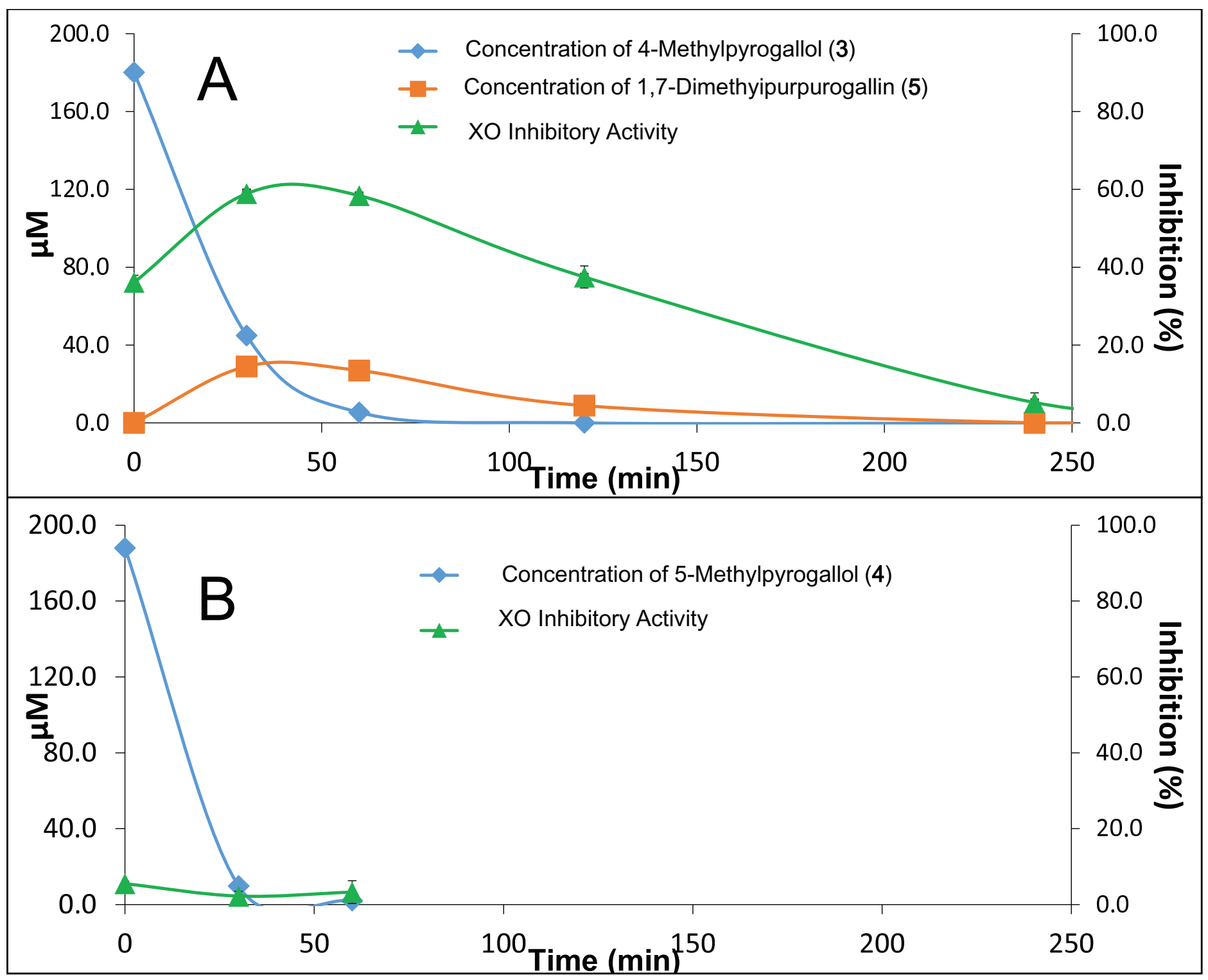

Fig. 6. 

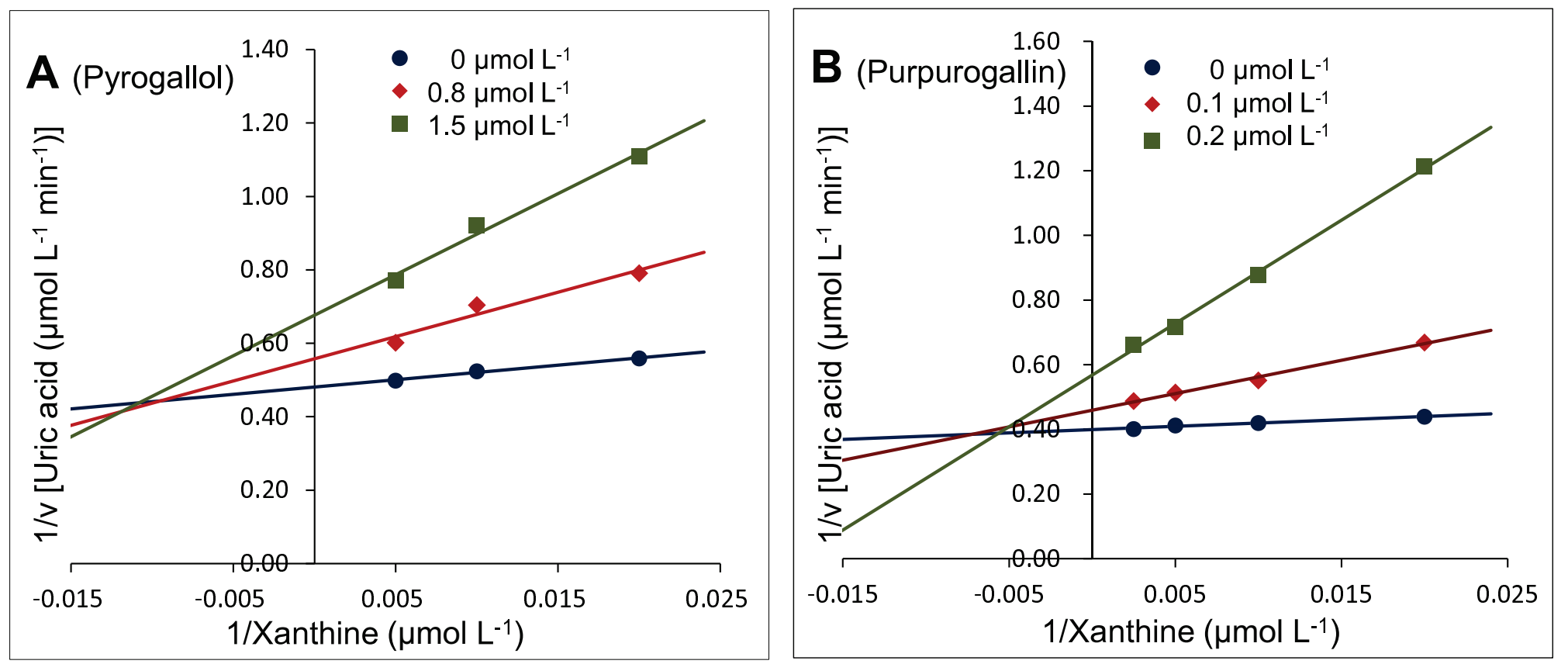

Fig. 7. 


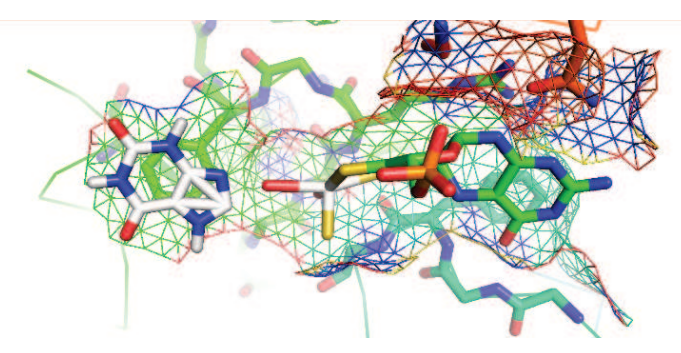

Xanthine

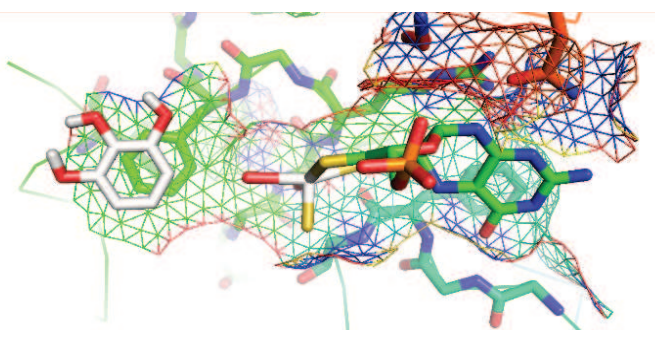

Pyrogallol (1)

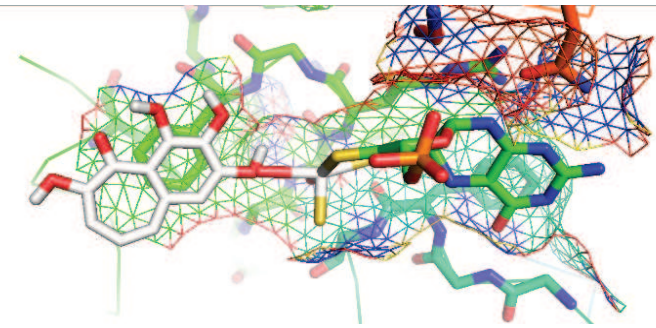

Purpurogallin (2)

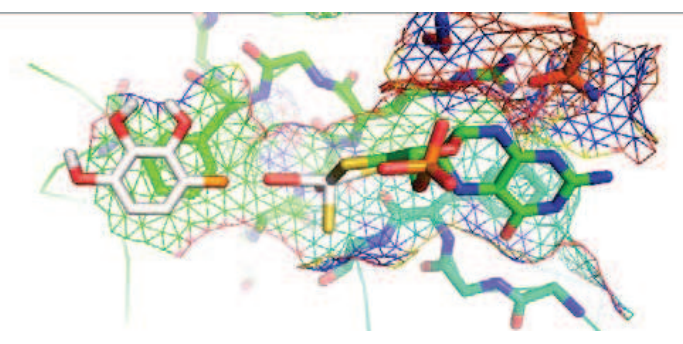

4-Methylpyrogallol (4)

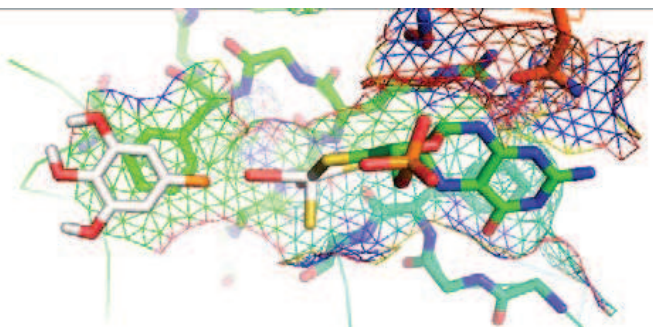

5-Methylpyrogallol (5)

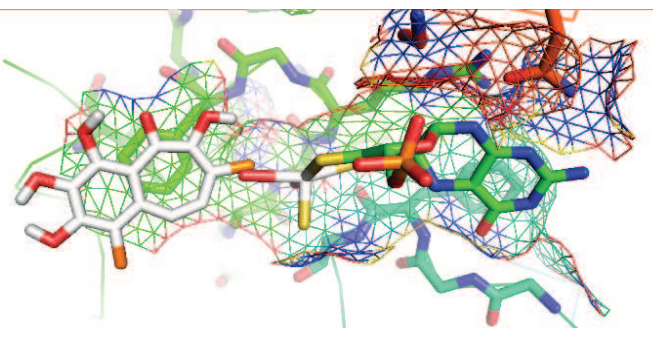

1,7-Dimethylpurpurogallin (6)

Fig. 8. 


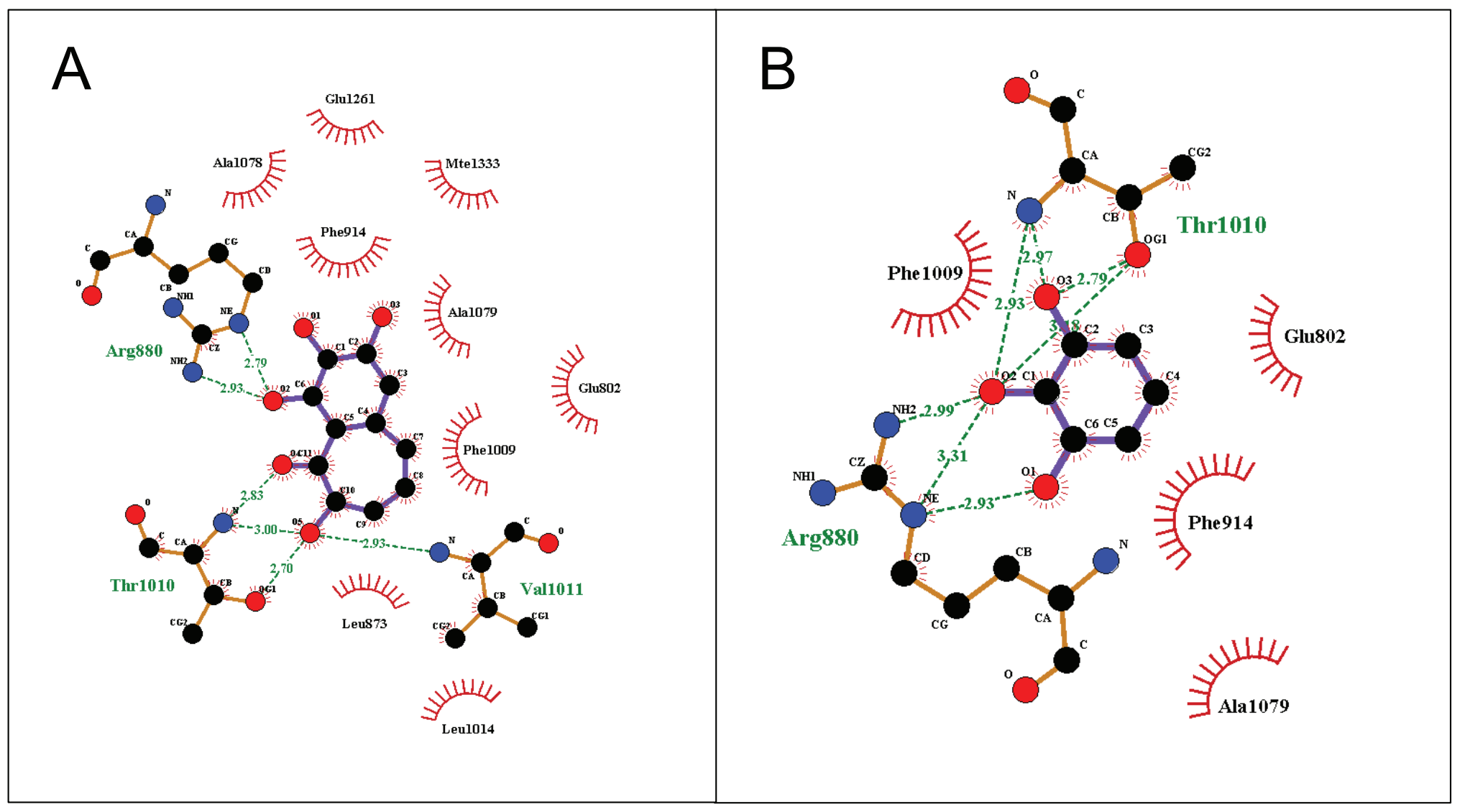

Fig. 9.

Figure9

A
B

$x_{1}$

(1)

(1)

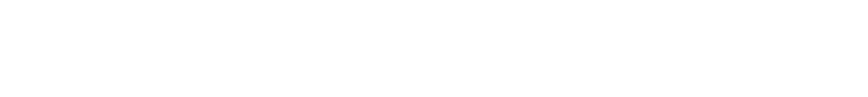

